\title{
PARAíso perdido
}

COMPLÔ CONTRA A AMÉRICA,

de Philip Roth. São Paulo: Companhia das Letras, 2005

EVERYMAN,

de Philip Roth. Boston, Houghton-Mifflin Co., 2006.

JOAQUIM TOLEDO JÚNIOR

"Um problema mais intrigante é como ele [o escritor] escreve a respeito daquilo que não aconteceu - como introduz elementos hipotéticos ou imaginados naquilo que é inspirado e controlado pela lembrança, e como o relembrado traz à tona a fantasia que dá forma a seu trabalho."

(PHILIP ROTH, Reading myself and others)

"Não era a primeira vez que ouvia aquelas histórias. A sabedoria de meu pai se expressa na forma narrativa, e seu repertório nunca foi extenso: família, família, família, Newark, Newark, Newark, judeus, judeus, judeus. Mais ou menos como o meu próprio."

(PHILIP RoTH, The facts)

Em uma foto de 1956, o cartunista Art Spiegelman está fantasiado de Cisco Kid - chapéu de abas largas, jaqueta e calças bordadas à mexicana, um perfeito caubói de tênis. Acima da foto, que compõe a breve HQ autobiográfica ironicamente intitulada Mein Kampf, o comentário: "apenas mais um baby-boomer". De fato, na típica fantasia de criança norte-americana, nada transparece do artista judeu que, vinte e cinco anos depois, decidirá recuperar em Maus, sua obra mais celebrada, as memórias do pai, sobrevivente do campo de concentração nazista de Auschwitz, na Polônia. "Escreva sobre o que você sabe', esse é o primeiro mandamento de qualquer manual para artistas", diz Spiegelman em Mein Kampf. "Mas para mim isso é um problema - na verdade, eu não sei de nada". Os relatos que são o material de Maus causam impacto sobre o pai, por causa do esforço de desbloquear na memória um conteúdo voluntária ou involuntariamente reprimido, e sobre o filho, que vê desmanchar em parte uma memória em certo sentido falsa: a infância segura e feliz em um país 
livre do anti-semitismo, que na Europa custara a vida de milhões de judeus, é contaminada pela proximidade da tragédia familiar. Ao migrar para os Estados Unidos, Vladek Spiegelman havia garantido ao filho uma infância tranqüila; para toda uma geração de judeus, foi possível crescer longe da estigmatização, eviver os anos prós peros do pós-guerra como "apenas mais umbaby-boomer" - como outros tantos filhos de italianos, irlandeses e (um pouco menos, certamente) afro-americanos, entre outros. Pelo menos até o momento em que veio à tona a particularidade da herança não simplesmente de norteamericano judeu, mas de judeu norte-americano.

É com um mesmo sentimento de assimilação total que Philip Roth, o personagem-narrador de Complô contra a América, inicia suas memórias sobre os anos 1940 e 1942, justamente os dois anos em que, na versão ficcional do escritor norte-americano Philip Roth ${ }^{1}$, o aviador popstar Charles Lindbergh - simpatizante do nazismo, condecorado pelo marechal Göring, dentro e fora das páginas do livro - assume a presidência dos Estados Unidos. Anos sombrios, como seria esperado, para uma família judia de classe média de Newark, Nova Jersey:

Lindbergh foi o primeiro americano famoso vivo que aprendi a odiarassim como o presidente Roosevelt foi o primeiro americano famoso vivo que me ensinaram a amar -, e assim a sua indicação pelo Partido Republicano para disputara presidência com Rooseveltem 1940 abalou, como nada abalara antes, a imensa segurança pessoal que eu sentia como coisa natural, sendo um menino americano filho de pais americanos que estudava numa escola americana e morava numa cidade americana num período em que a nação americana estava em paz com o mundo. (p. 17)

Assim como Roth, Philip nasceu em 1933 em meio a uma família judia perfeitamente integrada à sociedade norte-americana: o pai, Herman, corretor de seguros, e a mãe, Bess, dona de casa dedicada, conseguiram, com o esforço exigido pelos anos da Depressão, criar em torno da vida familiar uma atmosfera de estabilidade financeira e tranqüilidade emocional.As raízes propriamente judaicas dos Roth, assim como de toda a vizinhança do distrito de Weequahic, se revelavam, relata Philip, mais na persistência com que enfrentavam as eventuais dificuldades da vida do que na observância estrita dos costumes judaicos. Fãs de beisebol e do presidente Franklin Delano Roosevelt, era mais por caridade do que por compromisso com a causa que os Roth depositavam semanalmente uma pequena quantia na caixa de donativos que um senhor judeu de aparência arcaica vinha lhes trazer à porta, pedindo ajuda para a criação de uma pátria para os judeus. "Um pobre velho", diz Philip, "que nem mesmo com o passar dos anos conseguia enfiar na cabeça que havia três gerações já tínhamos uma pátria."
[1] Daqui em diante, irei me referir ao personagem Philip Roth como Philip, e ao escritor Philip Roth como Roth. 
[2] Roth, Philip. Reading myself and others. Nova York: Vintage International, p.31.
Roth deixou Nova Jersey e o bairro judeu no início dos anos 1950 para tornar-se um dos mais polêmicos escritores norte-americanos do pós-guerra. Goodbye, Columbus (1959), seu primeiro livro, reunia contos que foram recebidos pela crítica especializada como um excepcional trabalho de estréia - Saul Bellow o comparou a J. D. Salinger, S. Anderson e Gogol. No entanto, setores da comunidade judaica norteamericana consideraram que o livro jogava água no moinho do antisemitismo - textos como "Eli, o fanático" apresentavam os judeus de forma caricata, mais ou menos, afirmava-se, nos moldes da propaganda nazista. A acusação o perseguiria ao longo da carreira. Esse cisma na comunidade de leitores de Roth se radicaliza com a publicação, em 1969, de O complexo de Portnoy, que lhe valeu, por exemplo, a acusação de ter mobilizado "os mais crus e veneráveis estereótipos do repertório anti-semita" (Marie Syrkin), apesar de ter havido entre os leitores aqueles que viram no livro apenas "a maior e mais completa piada de judeu jamais contada" (Cristopher Lehmann-Haupt).Certamente, as paixões suscitadas por sua obra acabam deixando de lado um fato óbvio: Philip Roth é um escritor dotado de técnica narrativa rigorosa e consciente, e o controle exercido sobre o material artístico (e não apenas a natureza desse material: família, Newark, judeus) é responsável pela ambigüidade da recepção. Em artigo intitulado "Resposta à questão: 'Como você escreveu aquele livro, afinal'?"2, Roth comenta sobre $O$ complexo de Portnoy:

Foi apenas quando encontrei, na figura de um analisando transtornado, a voz que poderia falar tanto em nome do "garoto judeu" (com toda a carga de agressividade, voracidade e marginalidade que a expressão tem tanto para judeus como para gentios) e o "bom garoto judeu" (e o que o epiteto implica a respeito de repressão, respeitabilidade e conformidade social) éque fui capaz de dar forma a uma peça de ficção que apresentava o dilema de forma expressiva, e não apenas sintomática.

O que dá aos livros de Roth esse caráter polêmico é a proximidade com sua experiência real de vida - que Complô contra a América explora de forma radical e que inclui obviamente o fato de ter crescido no seio da comunidade judaica norte-americana. A série de romances que tem Nathan Zuckerman como narrador e personagem principal - entre os quais se destaca a trilogia que, na opinião de alguns críticos, é a realização de Roth que chegou mais próxima ao "sonho literário norteamericano" da great american novel: Pastoral americana (1997), Casei com um comunista (1998) e A marca humana (2000) - chega a sugerir algo como a elaboração de um alter ego atrás do qual Roth poderia se proteger das reações mais violentas de seus leitores. A biografia de Zuckerman e Roth se confundem, de fato, em pontos importantes: Zucker- 
man, em Zuckerman unbound (1979) vêa vida familiar desmoronar após publicar um romanceem que apresentava, sob uma luz nada edificante e de forma mal disfarçada, detalhes da vida de parentes próximos, como aconteceu a Roth com a publicação de O complexo de Portnoy; em livros posteriores, Zuckerman aparece desgostoso e recluso, mais ou menos como o próprio Roth se tornaria.A série de livros que tem como personagem e narrador Philip Roth - The facts: a writer's autobiography (1988), Decepção (1990), Patrimônio (1991), Operação Shylock (1993)e Complô contra a América (2004) —, no entanto, complicam essa interpretação: para um escritor que toma a si próprio como personagem, que utilidade teria um alter ego como Zuckerman (ou David Kepesh, de The breast, 1972; The professor of desire, 1977, e The dying animal, 2001) se não uma função literária? Como indicou Roth em entrevista à Paris Review: "Nathan Zuckerman é uma atuação. Trata-se da arte de assumir uma personagem (impersonate), não é? Essa é a dádiva fundamental do romancista"3.

Talvez então façamos maior justiça à obra de Roth ao considerarmos seu lugar na literatura americana, e a proximidade e distância que toma em relação à geração modernista anterior.

Warner Berthoff, em livro sobre a literatura americana de $1945 \mathrm{em}$ diante 4 - obra importante, embora talvez datada - identifica como traço comum à geração de escritores do pós-guerra (Saul Bellow, John Updike, E. L. Doctorow, Paul Theroux e o próprio Philip Roth, entre outros) um distanciamento das preocupações com uma identidade estilística, típica de autores modernistas como William Faulkner. Menos preocupados com a definição de uma dicção própria e exclusiva, é na pluralidade de vozes assumidas que se encontra o traço comum dessa geração - seé que, na expressão de Berthoff, essa "geração sem qualidades" tem algum traço em comum. O próprio Roth, em comentário de 2000 à obra de Saul Bellow, afirma, a respeito de The adventures of Augie March:

A transformação do romancista que publicou Dangling man em 1944 e The victim em 1947 no romancista que publicou The adventures of Augie March em 1957 é revolucionária. Bellow vira tudo do avesso: escolhas composicionais baseadas em princípios narrativos de harmonia e ordem [...] Em Augie March, uma enorme, positiva e livre concepção tanto do romance como do mundo que o romance representa é liberada de todas as limitações antes impostas $[. . .]^{5}$

Em sentido geral, a descrição encaixa-se perfeitamente com a própria obra de Roth. O tom lírico de "Goodbye, Columbus" em nada deixa antever a engenhosidade "jamesoniana" de Letting go (1962), do mesmo jeito que a trama policial intrincada de Operação Shylock está
[3] Reading myself and others, 123 . [4] Berthoff, Warner.Aliterature wit-
hout qualities: American writing since
1945. Los Angeles: Quantum Books,
1979.

[5] Roth, Philp. Shop Talk. Boston: Houghton Mifflin Company, 20o1. 

bath (1995). Na mesma entrevista à Paris Review, Roth definiu o desafio de começar um novo livro como a necessidade de superar a "paródia inconsciente" do livro anterior e chegar a uma "ruptura

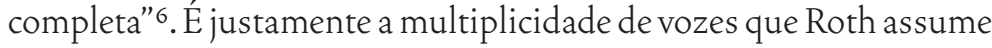
nos romances - estranhamente combinada à obsessão monotemática de sua matéria-prima - que faz de seu trabalho como escritor um dos mais instigantes da atualidade.

A eleição do isolacionista Lindbergh efetua um desrecalque no anti-semitismo adormecido dos gentios americanos. Sua campanha presidencial apóia-se no amplo receio dos norte-americanos diante da perspectiva de o país entrar na Segunda Guerra Mundial, e em discursos o aviador não deixa de afirmar, enfaticamente, que "os democratas beligerantes e os judeus" eram os maiores partidários do envolvimento de um país livre das ameaças do conflito numa guerra que não lhes dizia respeito. Numa tentativa de reafirmar para a família sua crença nos valores encarnados pela Carta dos Direitos - "todo homem nasce igual", etc. - e provar para a família que nada mudara mesmo com a eleição de um pró-nazista para a presidência (um acordo assinado com Hitler na Islândia teve o efeito prático de "transformar os Estados Unidos num membro da Tríplice Aliança do Eixo"), Herman Roth recusa-se a cancelar a viagem planejada à capital federal, Washington, e, a exemplo de conhecidos e parentes, dar início a um plano de emergência de fuga para o Canadá. No entanto, a persistência ingênua do pai - seu "incorrigível otimismo" - terá apenas o efeito de expor Philip, o irmão Sandy e a mãe à hostilidade crescente dos partidários do presidente Lindy. Expulsos do hotel e hostilizados sob cada monumento por onde passa, a família Roth depara-se com uma nova realidade:

Voltamos para a luz do dia e nos reunimos no degrau de cima. A haste alongada do monumento a Washington destacava-se a quase um quilômetro dali, do outro lado do lago artificial que se estendia até os terraços que conduziam ao Memorial Lincoln. Havia olmos plantados em torno do terreno todo. Era o panorama mais lindo que eu jamais vira, um paraíso patriótico, o Jardim do Éden americano, e lá estávamos nós, encolhidos, a família expulsa. (p.89)

O sonho americano dessa família, segunda e terceira geração de judeus americanos, passa a se desfazer. Os efeitos se farão sentir, em especial, na desarticulação da estrutura familiar e no distanciamento paulatino de Philip daquilo que seria - tivesse a história tomado outro rumo e Roosevelt se reeleito para um terceiro mandato - a tra- 
jetória típica do garoto judeu de classe média no pós-guerra, que a tranqüilidade confiante do caubói Art Spiegelman parece expressar. Bess deve renunciar à função de eixo da vida doméstica; Herman perde o emprego white-collare terá de se virar com o irmão no mercado de hortigranjeiros; Sandy decepcionará o pai ao tornar-se porta-voz de um programa do governo de "assimilação", cujo efeito prático é fragmentar a comunidade judaica ao forçar a transferência das famílias para regiões ermas do território nacional. E Philip, agora confuso e sem a supervisão da família, experimentará pela primeira vez as tentações da transgressão; aos nove anos de idade passará a ter pensamentos de anulação de sua identidade - seu plano desesperado para fazer desaparecer o terror consiste em fugir de casa e ir se abrigar, como órfão, num convento católico.

"O que levou $O$ complexo de Portnoy a ser simultaneamente um sucesso e um escândalo?", pergunta Roth em artigo sobre a representação do judeu na literatura judaica norte-americana contemporânea 7 . "Para começo de conversa, um romance disfarçado de confissão foi lido e julgado por um enorme número de leitores como se fosse uma confissão disfarçada de romance." A mesma ambigüidade é central para a construção de Complô contra a América. Um romance disfarçado de autobiografia que, não fossem os elementos fictícios evidentes, poderia ser vítima de confusão semelhante. O destino de Philip, se retoma um tema caro ao autor e constantemente presente em seus trabalhos - tanto ele quanto Alexander Portnoy, Nathan Zuckerman, David Kepesh, são diferentes faces daquilo que para Roth parece constituir a complexa psicologia do judeu americano ${ }^{8}$ - é tão profundamente enraizado na biografia de Roth que pode ser tomado por ela.

Mas as preocupações de Roth como escritor encontram-se em outro lugar, para além do memorialismo, da autobiografia ou da confissão. Philip experimenta um destino oposto ao de Portnoya obsessão sexual, o sentimento de culpa e rejeição que levam o segundo ao divã do dr. Spielvogel têm raízes na presença ostensiva do olhar materno, na repulsa pela figura frágil do pai, no sentimento de inferioridade diante das shiksas. O primeiro, por sua vez, verá a ruína justamente no desaparecimento dessa rede de proteção familiar. Relembrando a infância em The facts, Roth diz: "Segundo nossa crença tradicional, a família judaica era um abrigo inviolável contra toda forma de ameaça, do isolamento pessoal à hostilidade gentia". Outro destino cabe a Philip nos Estados Unidos de Charles A. Lindbergh.

O Complô contra a América é um exercício de imaginação literária de alcance monumental: o que seria dos Estados Unidos se, por alguns anos, sua história tivesse tomado outro rumo? E, mais importante, se
[7] Idem, p. 254 .

[8] A segunda metade do século XX, por vários motivos, diz Roth, é um período no qual, para determinado conjunto de escritores americanos judeus, "imaginar o que os judeus são e o que deveriam ser é tudo, menos uma atividade marginal" (idem, p. 279). 
[9] Os trechos de Everyman foram traduzidos pelo autor do artigo, porque a obra não foi publicada em português. pudesse não ter ocorrido a vitória na Segunda Guerra que, para dentro, fez do país um motivo de orgulho e, para fora, uma monstruosa potência econômica e militar? Que trajetórias de vida se modificariam? Que judeus seriam os judeus americanos se, em vez da prosperidade do pós-guerra, tivessem diante de si a ameaça de mais um pogrom? Os personagens de Philip Roth — judeus porque talvez também Roth tenha apreço pela primeira regra dos manuais para artistas ("escreva sobre o que você sabe") à qual Spiegelman se refere - têm de encarar esse futuro alternativo, no qual ninguém poderá se orgulhar de ser apenas mais umbaby-boomer.

"Mas quanto tempo deve um homem dedicar a relembrar seus dias de menino? E quanto a aproveitar o que há de bom na velhice?", pergunta o narrador de Everyman, trabalho mais recente de Roth, 9 explicitando as inquietações do personagem principal, um recordista em cirurgias cardíacas urgentes que vive seus últimos dias à beira do mar em um condomínio para idosos. Em busca da suposta tranqüilidade daquela paisagem familiar - a mesma cidade litorânea, tudo parece indicar, onde Philip passava as férias, aterrorizado com a possibilidade de encontrar um marinheiro alemão morto trazido pela maré, e onde Mickey Sabbath foi chorar, pela última vez, a morte precoce do irmão —, o protagonista anônimo acaba por defrontar-se com o vazio de sua vida. Para esse profissional medianamente bem-sucedido, vítima de três casamentos fracassados e pai de dois filhos que nutrem por ele um ódio que não esmorece nem mesmo diante de seu túmulo, a amargura vem da constatação tardia de que nem mesmo uma vida banal está livre da tragédia da decadência física e da morte do corpo.

Tema recorrente na obra de Roth, a morte aparece em Everyman despida da exuberância que tivera em $O$ teatro de Sabbath e da melancolia que reveste a morte precoce da amante de David Kepesh em O animal agonizante. Em frente do túmulo de seus pais, cujos restos mortais evocará para esconjurar a proximidade da morte, é o apego à permanência de algo concreto que lhe parecerá o último recurso: "os ossos [de seus pais] eram o único consolo que havia para alguém que não podia contar com a vida depois da morte e que sabia que Deus era uma ficção e que essa era a única vida que ele tinha." Distante do aprofundamento do desejo carnal trazido pela morte da amante de Mickey Sabbath, e do contraste que faz o corpo devastado pelo câncer de Consuela Castillo evocar a juventude e ovigor desaparecidos, a morte em Everymané simples sofrimento e aniquilação. O destino do protagonista ecoa, antes, o lamento de Ivan Ilitch, de Tolstói: "Mas o que é isso? Para quê? Não pode ser! É possível que a vida tenha sido tão sem sentido, tão lamentável? E se foi de fato tão lamentável e sem sentido, então por que morrer, por que agonizar? Tem algo de errado nisso". 
A obra de Roth nos faz desconfiar que, a seus olhos, há de fato algo de errado no envelhecimento e na morte. Ambos contrastam com o olhar sempre nostálgico dirigido à infância no seio da família (se excluirmos por um momento, evidentemente, as atribulações de Alexander Portnoy) e com a valorização do vigor físico (e, principalmente, sexual) de seus personagens. A morte é incompatível com a vida, um erro de planejamento da natureza. É dessa forma que, no funeral que abre Everyman, Howie recordará acima de tudo a inocência de seus dias de infância ao lado do irmão mais novo, "ressuscitando meticulosamente o mundo conforme ele existia antes da invenção da morte, a vida perpétua no Éden criado pelo pai, um paraíso de quatro e meio por doze metros, disfarçado de joalheria à moda antiga".

JOAQUIM TOLEDO JÚNIOR é mestrando no depto. de filosofia da FFLCH-USP e integrante do núcleo "Direito e Democracia" do Cebrap. 